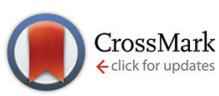

Cite this: Dalton Trans., 2016, 45 8320

Received 18th March 2016, Accepted 21st April 2016

DOI: $10.1039 / c 6 d t 01063 f$

www.rsc.org/dalton

\section{Expanding the family of bis-cyclometalated chiral-at-metal rhodium(III) catalysts with a benzothiazole derivative $\uparrow$}

\author{
Jiajia Ma, ${ }^{a}$ Xiaodong Shen, ${ }^{a}$ Klaus Harms ${ }^{a}$ and Eric Meggers ${ }^{\star a, b}$
}

\begin{abstract}
Synthetic access to previously elusive single enantiomers of an octahedral chiral-at-metal rhodium(III) complex containing two cyclometalated 2-phenylbenzothiazoles and two acetonitrile ligands is reported. The complex is a superior chiral Lewis acid catalyst compared to its benzoxazole congener which can be rationalized with a higher steric congestion around the coordination sites.
\end{abstract}

Chiral Lewis acids play an important role in asymmetric catalysis because many reactions are amenable to Lewis acid activation. ${ }^{1}$ Recently, we introduced a new class of chiral Lewis acids based on octahedral iridium(III) ${ }^{2-7}$ and rhodium(III) $)^{8-11}$ complexes which draw their chirality exclusively from the metal-centered chirality (metal centrochirality). ${ }^{12,13}$ These chiral-only-at-metal complexes are cyclometalated by two 5-tert-butyl-2-phenylbenzoxazoles or the analogous benzothiazole ligands in addition to two exchange-labile acetonitriles, which generates a $C_{2}$-symmetric, propeller-type geometry.

Whereas the iridium complexes $\Lambda / \Delta$-IrO and $\Lambda / \Delta$-IrS have been demonstrated to be excellent catalysts for visible light induced photoredox reactions, ${ }^{3,4,6,7}$ the rhodium congener $\Lambda / \Delta$-RhO features advantages for regular Lewis acid catalysis, ${ }^{8-10}$ apparently due to a more rapid ligand exchange kinetics (Table 1). We expected that the related complex $\Lambda / \Delta$-RhS, in which the coordinating benzoxazole moieties are replaced by benzothiazoles, should provide a higher asymmetric induction due to an increased bond length of $\mathrm{C}-\mathrm{S}$ over $\mathrm{C}-\mathrm{O}$ which will position the two tert-butyl groups somewhat closer to the substrate coordination site. Here we disclose the previously elusive access to the enantiomerically pure benzothiazole complexes $\Lambda$ - and $\Delta$-RhS, characterize their structures and configurational

\footnotetext{
${ }^{a}$ Philipps-Universität Marburg, Hans-Meerwein-Strasse 4, 35043 Marburg, Germany. E-mail:meggers@chemie.uni-marburg.de

${ }^{b}$ College of Chemistry and Chemical Engineering, Xiamen University, Xiamen 361005, People's Republic of China

$\dagger$ Electronic supplementary information (ESI) available: Experimental details and analytical data. CCDC 1455731 and 1455732. For ESI and crystallographic data in CIF or other electronic format see DOI: 10.1039/c6dt01063f
}

Table 1 Overview of bis-cyclometalated, chiral-only-at-metal iridium and rhodium catalysts ${ }^{a}$

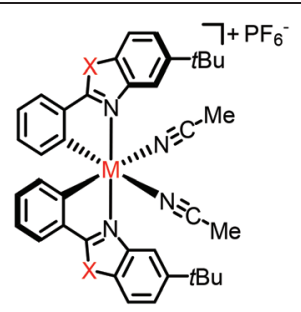

$\Lambda$

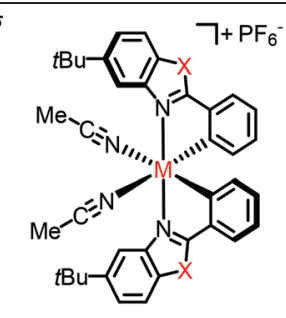

$\Delta$

\begin{tabular}{lllll}
\hline Entry & Complex & M & X & Remarks \\
\hline 1 & $\Lambda$ - and $\Delta$-IrO & Ir & O & Ref. 2 and 4 \\
2 & $\Lambda$ - and $\Delta$-IrS & Ir & S & Ref. 3 and 5-7 \\
3 & $\Lambda$ - and $\Delta$-RhO & Rh & O & Ref. 8-11 \\
4 & $\Lambda$ - and $\Delta$-RhS & Rh & S & This study
\end{tabular}

${ }^{a}$ Synthesis by an auxiliary-mediated strategy.

stability, and demonstrate their excellent performance as asymmetric catalysts.

The auxiliary-mediated synthesis ${ }^{14-18}$ starts with rhodium trichloride hydrate which is first converted into rac-RhS in a yield of $73 \%$ by reaction with 2 equiv. of 5-tert-butyl-2-phenylbenzothiazole (1), followed by a treatment with 1.2 equiv. of $\mathrm{AgPF}_{6}$ in $\mathrm{MeCN}$ (Fig. 1). The complex rac-RhS is then reacted with the monofluorinated salicyloxazoline $(S)-2^{19}$ to provide a diastereomeric mixture of $\Lambda-(S)-3$ and $\Delta-(S)-3$ which can be resolved into pure diastereomers ( $46 \%$ each) based on their different solubilities in EtOH or by silica gel chromatography, or a combination thereof depending on the reaction scale. Configurations were assigned based on the crystal structure of $\Lambda-(S)-3$ as shown in Fig. 2. Finally, starting with $\Lambda-(S)-3$ and $\Delta-(S)-3$, an acid induced replacement of the coordinated auxiliary ligand with two acetonitriles under retention of the configuration affords the individual enantiomers $\Lambda$-RhS $(85 \%)$ and $\Delta$-RhS $(80 \%)$. The key aspect of this auxiliary-mediated synthesis is the fluorinated auxiliary $(S)-2$ which was first 


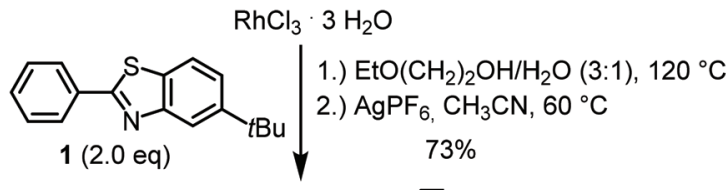<smiles></smiles><smiles>O=P(O)(O)[C@H]1COC(c2c(O)cccc2F)=N1</smiles>
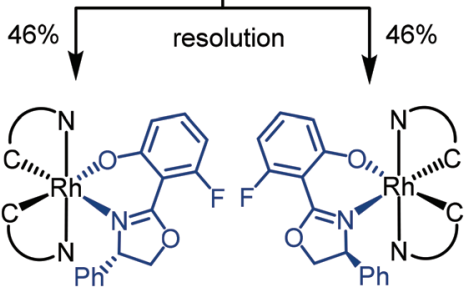

$\Lambda-(S)-3$

$\Delta-(S)-3$

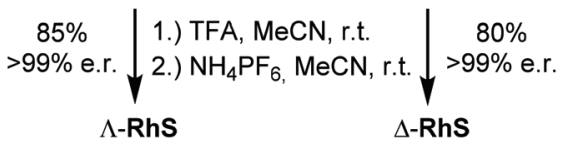

Fig. 1 Auxiliary-mediated synthesis of $\Lambda$ - and $\Delta$-RhS

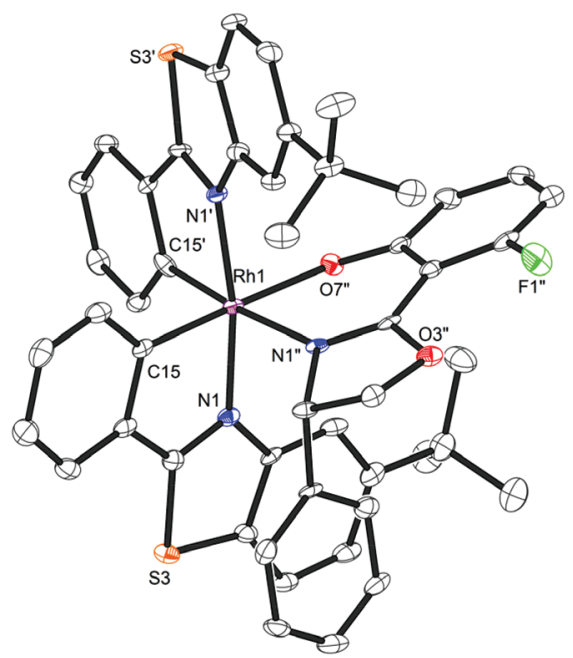

Fig. 2 Crystal structure of the auxiliary complex $\Lambda$-(S)-3. ORTEP drawing with 50\% thermal ellipsoids. CCDC number 1455732.

introduced by Ceroni and co-workers. ${ }^{19}$ All other tested auxiliaries did not provide intermediate rhodium auxiliary complexes with distinct solubilities and were not stable enough for a resolution via silica gel chromatography.
The CD spectra of the complexes $\Lambda$ - and $\Delta$-RhS are shown in Fig. 3, and confirm their mirror-imaged structures. HPLC performed on a chiral stationary phase validates the high enantiomeric purity of the individual enantiomers (Fig. 4). ${ }^{20}$ For the $\Delta$-enantiomer an er of 99.9: 0.1 was determined, while peak tailing prevents an accurate validation of the $\Lambda$-enantiomer and an er of $>99: 1$ was estimated.

Fig. 5 shows the superimposed crystal structures of $\Lambda$-RhS and mirror-imaged $\Delta$-RhO, not only confirming the assigned metal-centered configuration of $\Lambda$-RhS, but also revealing the differences in how the two tert-butyl groups flank the coordination site around the two exchange-labile acetonitrile ligands. In comparison with RhO, the tert-butyl groups of RhS are in closer proximity to the labile acetonitriles as quantified by a $0.9 \AA$ shorter intramolecular distance between the quaternary carbons of the two tert-butyl groups in RhS (10.5 $⿱$ ) over RhO (11.4 $\AA$ ). This is consistent and analogous with a comparison of the related benzoxazole and benzothiazole iridium complexes. ${ }^{3,5}$

The increased steric hindrance provided by the two tertbutyl groups should make RhS an improved asymmetric catalyst for many applications. This is confirmed by the preliminary results shown in Fig. 6. In both enantioselective Michael addition $^{8}$ and a photoinduced enantioselective radical reaction, ${ }^{11}$ the determined enantioselectivities are appreciably

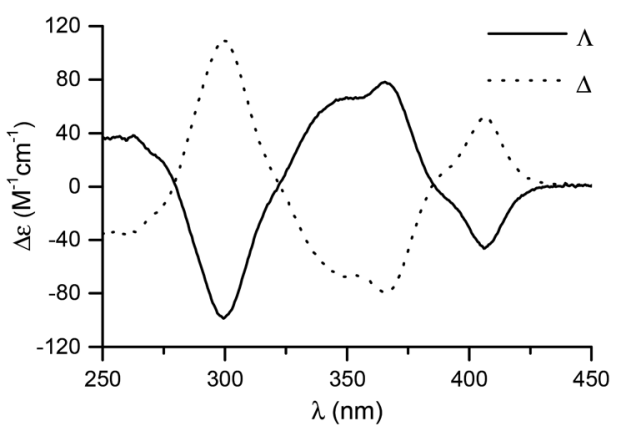

Fig. $3 \mathrm{CD}$ spectra of $\Lambda$ - and $\Delta$-RhS recorded in $\mathrm{CH}_{3} \mathrm{OH}: \mathrm{CH}_{2} \mathrm{Cl}_{2} 4: 1$.

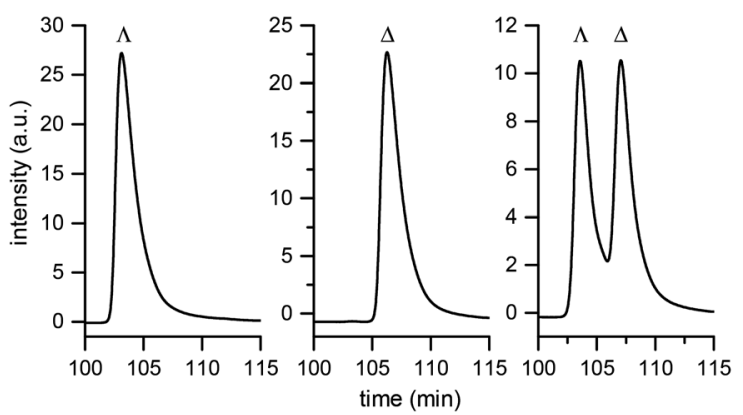

Fig. 4 HPLC traces of racemic, $\Lambda$ - and $\Delta$-RhS. HPLC conditions: Daicel CHIRALPAK IB, $250 \times 4.6 \mathrm{~mm}$, column temp. $=25^{\circ} \mathrm{C}, \lambda_{\text {abs }}=254 \mathrm{~nm}$, flow rate $=0.6 \mathrm{~mL} \mathrm{~min}{ }^{-1}$, solvent $A=0.1 \%$ aqueous TFA, solvent $B=$ $\mathrm{MeCN}$, gradient $=40 \%$ to $50 \% \mathrm{~B}$ in $180 \mathrm{~min}$. 


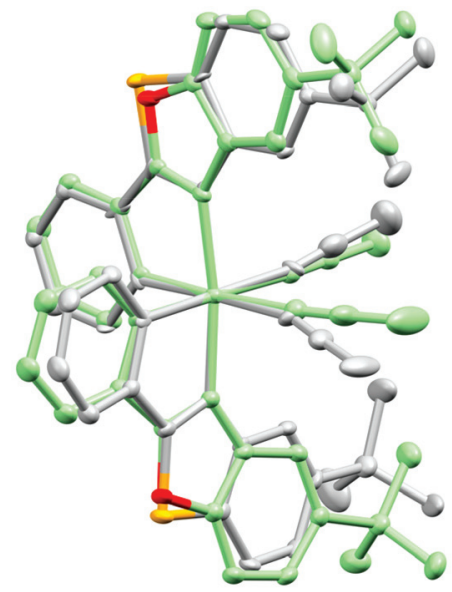

Fig. 5 Superimposed crystal structure of $\Lambda$-RhS (grey) with inverted $\Delta$-RhO (green). Fitted is the central metal together with the metal-bound atoms. Atoms are displayed as $50 \%$ thermal ellipsoids. CCDC number 1455731 ( $\Lambda$-RhS).
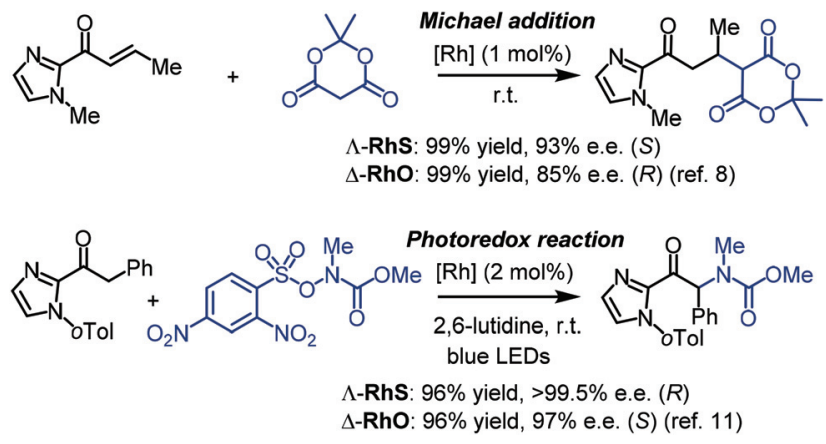

Fig. 6 Comparison of catalytic performances of $\Lambda$-RhS and $\Delta$-RhO.

higher for the benzothiazole (RhS) over the benzoxazole (RhO) catalyst. $^{21}$

In conclusion, here we reported a new chiral-at-metal benzothiazole complex $\Lambda / \Delta$-RhS which expands the family of bis-cyclometalated rhodium(III) complexes for applications in asymmetric catalysis. Compared to the previously reported benzoxazole complex $\Lambda / \Delta$-RhO, the benzothiazole ligands in $\Lambda / \Delta$-RhS provide a higher steric congestion around the labile acetonitrile ligands, thereby making $\Lambda / \Delta$-RhS a superior asymmetric catalyst. Applications of the new chiral Lewis acid catalyst to challenging asymmetric transformations are underway in our laboratory.

We thank the German Research Foundation (DFG) for financial support of this research (ME 1805/13-1).

\section{Notes and references}

1 Reviews and accounts on different aspects of chiral Lewis acid catalysis: (a) K. Narasaka, Synthesis, 1991, 1-11; (b) S. Saito and H. Yamamoto, Chem. Commun., 1997,
1585-1592; (c) K. A. Jørgensen, M. Johannsen, S. Yao, H. Audrain and J. Thorhauge, Acc. Chem. Res., 1999, 32, 605-613; (d) J. S. Johnson and D. A. Evans, Acc. Chem. Res., 2000, 33, 325-335; (e) G. Desimoni, G. Faita and K. A. Jørgensen, Chem. Rev., 2006, 106, 3561-3651; (f) S. Kobayashi and C. Ogawa, Chem. - Eur. J., 2006, 12, 5954-5960; (g) S. Kanemasa, M. Hasegawa and F. Ono, Chem. Rec., 2007, 7, 137-149; (h) J. Christoffers, G. Koripelly, A. Rosiak and M. Rössle, Synthesis, 2007, 1279-1300; (i) M. North, D. L. Usanov and C. Young, Chem. Rev., 2008, 108, 5146-5226; (j) P. Li and H. Yamamoto, Top. Organomet. Chem., 2011, 37, 161-183; (k) J. Zhou and Y. Tang, Top. Organomet. Chem., 2011, 36, 287-312; (l) L. C. Dias, E. C. de Lucca Jr., M. A. B. Ferreira and E. C. Polo, J. Braz. Chem. Soc., 2012, 23, 2137-2158; (m) H. Yamamoto, Top. Organomet. Chem., 2013, 44, 315-334.

2 H. Huo, C. Fu, K. Harms and E. Meggers, J. Am. Chem. Soc., 2014, 136, 2990-2993.

3 H. Huo, X. Shen, C. Wang, L. Zhang, P. Röse, L.-A. Chen, K. Harms, M. Marsch, G. Hilt and E. Meggers, Nature, 2014, 515, 100-103.

4 C. Wang, Y. Zheng, H. Huo, P. Röse, L. Zhang, K. Harms, G. Hilt and E. Meggers, Chem. - Eur. J., 2015, 21, 73557359.

5 X. Shen, H. Huo, C. Wang, B. Zhang, K. Harms and E. Meggers, Chem. - Eur. J., 2015, 21, 9720-9726.

6 H. Huo, C. Wang, K. Harms and E. Meggers, J. Am. Chem. Soc., 2015, 137, 9551-9554.

7 C. Wang, J. Qin, X. Shen, R. Riedel, K. Harms and E. Meggers, Angew. Chem., Int. Ed., 2016, 55, 685-688.

8 C. Wang, L.-A. Chen, H. Huo, X. Shen, K. Harms, L. Gong and E. Meggers, Chem. Sci., 2015, 6, 1094-1100.

9 Y. Huang, L. Song, L. Gong and E. Meggers, Chem. - Asian J., 2015, 10, 2738-2743.

10 Y. Tan, W. Yuan, L. Gong and E. Meggers, Angew. Chem., Int. Ed., 2015, 54, 13045-13048.

11 X. Shen, K. Harms, M. Marsch and E. Meggers, submitted for publication.

12 For reviews on different aspects of metal-centered chirality, see: (a) J.-L. Pierre, Coord. Chem. Rev., 1998, 178-180, 11831192; (b) U. Knof and A. von Zelewsky, Angew. Chem., Int. Ed., 1999, 38, 302-322; (c) P. D. Knight and P. Scott, Coord. Chem. Rev., 2003, 242, 125-143; (d) H. Amouri and M. Gruselle, Chirality in Transition Metal Chemistry, Wiley, Chichester, UK, 2008; (e) E. Meggers, Eur. J. Inorg. Chem., 2011, 2911-2926; ( $f$ ) J. Crassous, Chem. Commun., 2012, 48, 9684-9692; (g) E. C. Constable, Chem. Soc. Rev., 2013, 42, 1637-1651; (h) A. von Zelewsky, Chimia, 2014, 68, 297-298.

13 For reviews covering chiral-at-metal complexes in catalysis, see: (a) H. Brunner, Angew. Chem., Int. Ed., 1999, 38, 11941208; (b) M. Fontecave, O. Hamelin and S. Ménage, Top. Organomet. Chem., 2005, 15, 271-288; (c) E. B. Bauer, Chem. Soc. Rev., 2012, 41, 3153-3167; (d) L. Gong, L.-A. Chen and E. Meggers, Angew. Chem., Int. Ed., 2014, 53, 10868-10874; (e) Z.-Y. Cao, W. D. G. Brittain, J. S. Fossey and F. Zhou, Catal. Sci. Technol., 2015, 5, 3441-3451. 
14 E. Meggers, Chem. - Eur. J., 2010, 16, 752-758.

15 L. Gong, M. Wenzel and E. Meggers, Acc. Chem. Res., 2013, 46, 2635-2644.

16 M. Helms, Z. Lin, L. Gong, K. Harms and E. Meggers, Eur. J. Inorg. Chem., 2013, 4164-4172.

17 L.-A. Chen, W. Xu, B. Huang, J. Ma, L. Wang, J. Xi, K. Harms, L. Gong and E. Meggers, J. Am. Chem. Soc., 2013, 135, 10598-10601.

18 For related studies from other groups on auxiliary mediated synthesis of chiral, non-racemic metal complexes, see: (a) C. F. Liu, N. C. Liu and J. C. Bailar, Inorg. Chem., 1964, 3, 1085-1087; (b) U. Koelle, K. Bücken and U. Englert, Organometallics, 1996, 15, 1376-1383; (c) D. Hesek, Y. Inoue, S. R. L. Everitt, H. Ishida, M. Kunieda and M. G. B. Drew, Chem. Commun., 1999, 403404; (d) D. Hesek, Y. Inoue, H. Ishida, S. R. L. Everitt and M. G. B. Drew, Tetrahedron Lett., 2000, 41, 2617-2620; (e) D. Hesek, Y. Inoue, S. R. L. Everitt, H. Ishida, M. Kunieda and M. G. B. Drew, Inorg. Chem., 2000, 39, 317324; $(f)$ F. Pezet, J.-C. Daran, I. Sasaki, H. Aït-Haddou and G. G. A. Balavoine, Organometallics, 2000, 19, 4008-4015; (g) O. Chepelin, J. Ujma, X. Wu, A. M. Z. Slawin, M. B. Pitak, S. J. Coles, J. Michel, A. C. Jones, P. E. Barran and P. J. Lusby, J. Am. Chem. Soc., 2012, 134, 19334-19337; (h) D. L. Davies, K. Singh, S. Singh and B. Villa-Marcos, Chem. Commun., 2013, 49, 6546-6548.

19 E. Marchi, R. Sinisi, G. Bergamini, M. Tragni, M. Monari, M. Bandini and P. Ceroni, Chem. - Eur. J., 2012, 18, 8765-8773.
20 For other reports on non-racemic, chiral-at-metal octahedral rhodium(III) complexes, see: (a) A. H. Krotz, L. Y. Kuo, T. P. Shields and J. K. Barton, J. Am. Chem. Soc., 1993, 115, 3877-3882; (b) A. Sitlani, C. M. Dupureur and J. K. Barton, J. Am. Chem. Soc., 1993, 115, 12589-12590; (c) L. Ghizdavu, B. Kolp, A. von Zelewsky and H. StoeckliEvans, Eur. J. Inorg. Chem., 1999, 1271-1279; (d) L. Ghizdavu, A. von Zelewsky and H. Stoeckli-Evans, Eur. J. Inorg. Chem., 2001, 993-1003; (e) L. Ghizdavu, O. Lentzen, S. Schumm, A. Brodkorb, C. Moucheron and A. Kirsch-De Mesmaeker, Inorg. Chem., 2003, 42, 19351944; $(f)$ N. Yoshinari and T. Konno, Inorg. Chem., 2008, 47, 7450-7452; (g) A. Damas, J. Moussa, M. N. Rager and H. Amouri, Chirality, 2010, 22, 889-895; (h) S. Mollin, S. Blanck, K. Harms and E. Meggers, Inorg. Chim. Acta, 2012, 393, 261-268; (i) S. Mollin, R. Riedel, K. Harms and E. Meggers, J. Inorg. Biochem., 2015, 148, 11-21; (j) R. Rajaratnam, E. K. Martin, M. Dörr, K. Harms, A. Casini and E. Meggers, Inorg. Chem., 2015, 54, 8111-8120.

21 For asymmetric catalysis with octahedral rhodium(III) complexes, see also: (a) H. Nishiyama, H. Sakaguchi, T. Nakamura, M. Horihata, M. Kondo and K. Itoh, Organometallics, 1989, 8, 846-848; (b) Y. Motoyama, H. Narusawa and H. Nishiyama, Chem. Commun., 1999, 131-132; (c) D. Cuervo, M. P. Gamasa and J. Gimeno, J. Mol. Catal. A: Chem., 2006, 249, 60-64; (d) J.-i. Ito and H. Nishiyama, Synlett, 2012, 509-523; (e) T. Wang, J.-L. Niu, S.-L. Liu, J.-J. Huang, J.-F. Gong and M.-P. Song, Adv. Synth. Catal., 2013, 355, 927-937. 